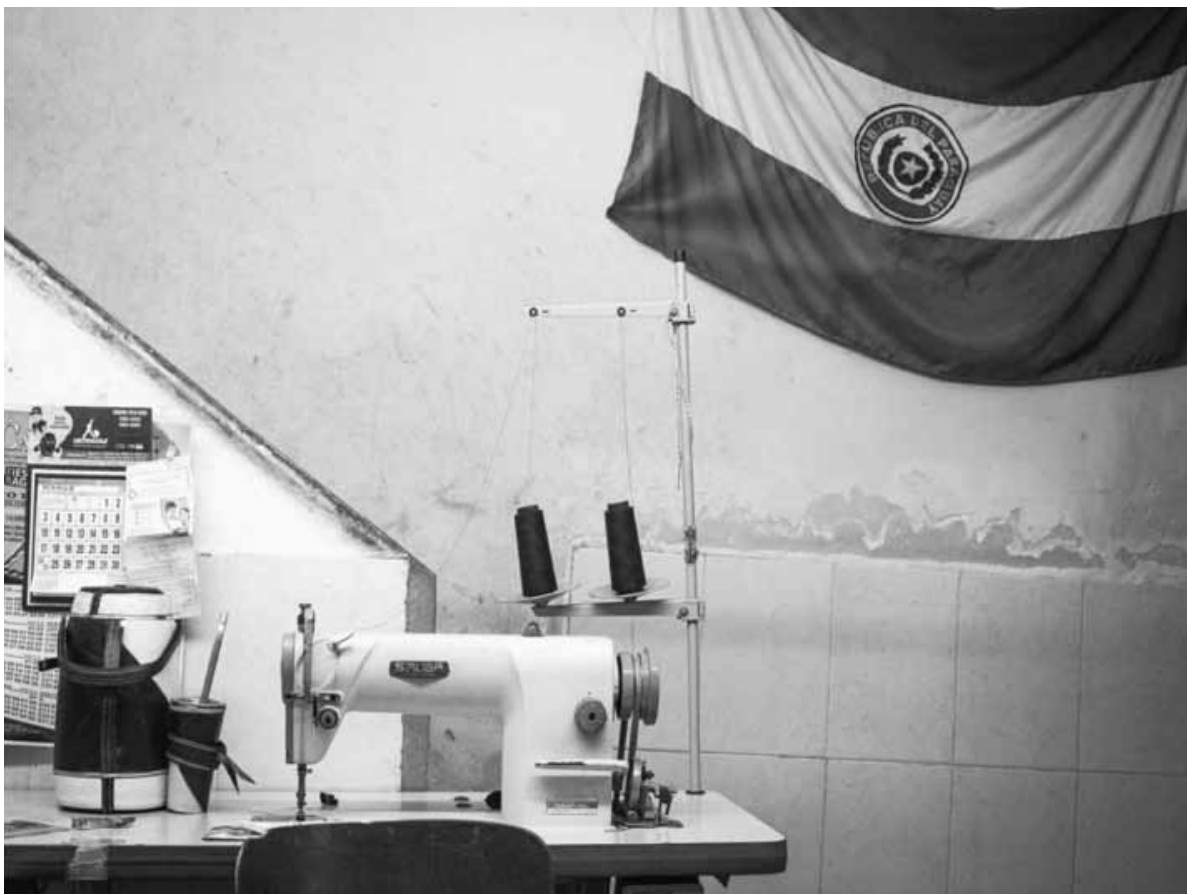

Foto: Tiago Rangel Côrtes.

Oficina de Costura de paraguaios na Vila Medeiros, São Paulo. Detalhe do tererê, companheiro de todas as horas.

\title{
Migrantes na costura em São Paulo Paraguaios, bolivianos e brasileiros na indústria de confecções
}

\author{
Tiago Rangel Côrtes * \\ Carlos Freire da Silva **
}

A dinâmica atual da indústria de confeç̧ões em São Paulo se confunde com a história dos fluxos de migrantes que em diferentes momentos a compuseram. Em seu surgimento a partir da década de 1930 e desenvolvimento ao longo do século passado, esteve relacionada a diversos contingentes migratórios: sírios,

* Mestre em Sociologia pela USP e Técnico do Observatório do Trabalho/DIEESE.

** Pesquisador, doutor em Sociologia pela USP. 
libaneses, judeus, coreanos; e também nacionais, principalmente do nordeste do país ${ }^{1}$. A partir do final dos anos 1970, sobretudo ao longo da década de 1990 e de 2000 , destaca-se a migração transnacional de trabalhadores que operam máquinas de costura. Dentre diversas nacionalidades, bolivianos e paraguaios têm afluído em intensidade para a região e se inserido nesse segmento produtivo, fenômeno importante para a vida urbana da Região Metropolitana de São Paulo (RMSP).

O que tem despertado um grande debate público sobre esses fluxos, em especial em torno dos bolivianos, não é tanto o volume absoluto de pessoas, senão a forma particular de inserção na cidade: a tendência à especialização no setor de confecções e as condições precárias de trabalho às quais estão sujeitos (segundo inferências do Censo de 2010, 29,9\% dos paraguaios e 42,6\% dos bolivianos residentes na RMSP trabalham como operadores de máquina de costura ${ }^{2}$ ). As formas extremas de exploração dos migrantes no setor têm sido amplamente veiculadas pelas mídias, pesquisadas nas universidades, denunciadas por organizações de direitos humanos e causado ações do Ministério do Trabalho e Emprego (MTE) e do Ministério Público do Trabalho (MPT). Porém, a ênfase exclusiva ao caso de bolivianos tem causado algumas distorções no debate, como atribuir as condições de trabalho em São Paulo à origem nacional dos migrantes. Nesse sentido, a participação dos paraguaios no setor é algo relativamente pouco tematizada, embora não ignorada em diferentes estudos.

O objetivo deste artigo será justamente discutir os migrantes transnacionais que gravitam em torno das oficinas na RMSP. Partindo da hipótese de Sylvain Souchaud (2012) de que a inserção de migrantes no segmento não se constitui como um nicho étnico, mas sim um nicho de mercado para diferentes grupos, sugere-se a existência de uma afinidade no modo como se organizam os fluxos migratórios e a estrutura produtiva do segmento (FREIRE, 2008; CÔRTES, 2013). Como procuraremos demonstrar, as condições de trabalho, as violações e as situações a que são submetidos (e às quais se submetem) os trabalhadores não são características ligadas à origem nacional desses migrantes, mas decorrem da maneira como se associa a migração e a organização do trabalho na cadeia produtiva da indústria de confecções. Destaca-se especialmente a posição de poder e controle das grandes empresas varejistas e atacadistas, que auferem os maiores ganhos na cadeia, responsáveis por ditar o ritmo da produção, definir os estilos e tipos de vestimentas, em um modelo de gestão produtiva em que não são responsabilizadas pelos contratos de trabalho dos operadores das máquinas de costura.

O texto está dividido em dois momentos. No primeiro abordaremos o desenvolvimento recente da indústria de confecções. Procuraremos mostrar que, embora possa haver semelhanças entre as oficinas de costura atuais e os sweatshops do século XIX (GREEN, 1998), isso não quer dizer que as oficinas representem um anacronismo residual no setor. A situação atual de organização do segmento através da proliferação de pequenas células produtivas, em que 
frequentemente coincidem espaços de moradia e trabalho que contam com migrantes muitas vezes em situações precárias, coincide com o processo de modernização e desenvolvimento global da indústria de confecções. Há uma afinidade entre os modos como se estruturam a produção pulverizada de vestimentas em oficinas de costura e os atuais fluxos migratórios transnacionais - dinamizados, no caso da RMSP, por bolivianos e paraguaios e, em menor medida, por peruanos e migrantes de outras nacionalidades.

Num segundo momento, traçaremos algumas comparações entre a organização de oficinas de costura de bolivianos, paraguaios e brasileiros e o perfil de seus trabalhadores. Como foi dito, embora a ênfase dada ao debate tenha pautado quase exclusivamente o caso dos bolivianos, a maior parte dos trabalhadores do segmento são mulheres brasileiras e, desde os anos 1980, há registros da participação de paraguaios, tendo crescido exponencialmente a partir de meados dos anos 2000. O grande diferencial das oficinas de migrantes se deve ao modo pelo qual se articulam as condições de trabalho, a moradia e a intermediação migratória. Ao mesmo tempo em que essas características favoreceram as oficinas de costura a se constituírem como um nicho de mercado para migrantes, facilitando a inserção dos trabalhadores na vida urbana de São Paulo, esses termos se situam na base das autuações dos órgãos de fiscalização do trabalho. Ao considerar a presença de paraguaios no setor, buscaremos deslocar a problematização étnica ou da origem nacional, com o objetivo de compreender as semelhanças e diferenças dos trabalhadores migrantes e brasileiros que operam máquinas de costura, ou que trabalham em torno dessa atividade específica.

\section{Oficinas de costura e mobilidades migratórias}

De acordo com as informações da Rais ${ }^{3}$, a Confeç̧ão de artigos do vestuário e acessórios representa o grupo de atividade de maior estoque de empregos formais na indústria de transformação da RMSP. Em 2012, constituía $7,5 \%$ do total dos empregos na indústria. Dos 93.697 registros de vínculos de emprego, $97,6 \%$ eram de brasileiros; dos $2,4 \%$ restantes, $1,7 \%$ era composto por bolivianos, $0,4 \%$ por paraguaios e os demais $0,3 \%$ dispersos entre mais de quinze diferentes nacionalidades. Essa simples constatação sobre o mercado de trabalho formal da RMSP indica duas questões importantes: primeiro, a relevância desse segmento industrial para a economia urbana da cidade; e, em segundo lugar, a presença de migrantes transnacionais, em especial bolivianos e paraguaios, sem deixar de considerar que o segmento é composto majoritariamente por trabalhadores brasileiros.

É necessário ponderar que essa indústria é marcada fortemente pelo trabalho informal (logo, não computado pelos dados da Rais), de modo que o 
número de empregos no segmento é seguramente muito maior. Ao se analisar exclusivamente os operadores de máquinas de costura formais na RMSP em $2012^{4}$, havia 39.380 vínculos, dos quais $96,1 \%$ (37.289) eram compostos por brasileiros, 3,0\% (1.185) por bolivianos e 0,7\% (288) por paraguaios, e mais de 15 nacionalidades se dividiam entre os $0,2 \%(78)$ restantes. Quando contrastamos as informações da Rais com os microdados da amostra do Censo de 2010, que captam trabalhadores formais e informais, vemos que as estimativas para Operador de máquina de costura apresentam números bem maiores, seriam 156.695 pessoas na RMSP, sendo 91,1\% brasileiros, 7,5\% bolivianos (11.807 pessoas) e $0,8 \%$ paraguaios (1.242 pessoas).

Considerando a incidência de migrantes neste segmento específico da indústria, podemos pensar as oficinas como um mecanismo que opera em dois sentidos: primeiro, através das oficinas de costura se ativam redes de migração transnacionais, possibilitando a circulação de trabalhadores ao oferecer um caminho de inserção na dinâmica econômica da cidade. Em segundo, as oficinas possibilitam a gestão do trabalho na indústria de confecções associada a sua produtividade, pois oferecem uma forma de organização da produção adequada à sazonalidade e flexibilidade do setor; livra as empresas que coordenam as cadeias produtivas do peso da manutenção de um grande quadro fixo de trabalhadores para um mercado bastante flutuante; e desresponsabilizam as maiores empresas pelas condições de trabalho desenvolvidas no setor ao descaracterizar a relação de trabalho, que passa a se constituir juridicamente como uma relação de prestação de serviços (FREIRE, 2008; CÔRTES, 2013). Esses sentidos compõem um modo de inserção dos migrantes, através das oficinas, que engendra formas específicas de exploração do trabalho.

As oficinas de costura são mecanismos através dos quais se impulsionou a mobilidade migratória para a região nos últimos anos, de modo que há uma afinidade entre essas dinâmicas migratórias e a indústria de confecções da RMSP. Sobre o assunto, Sylvain Souchaud (2012) argumenta que a despeito da grande concentração de migrantes bolivianos no setor, isto não pode ser tomado como um nicho étnico, ou seja, a reincidência da atuação profissional de migrantes não decorre de características ligadas à origem nacional dos trabalhadores. Ao invés disto, o autor propõe que as oficinas se constituíram em um nicho econômico para migrantes de diferentes origens. De acordo com Souchaud, elas podem ser pensadas como lugares de inserção e ascensão social em que numerosos estrangeiros realizam seus projetos migratórios ${ }^{5}$, seja de tornar-se dono de oficina ou de acumular recursos para investir em seu país de origem. De fato, essa é uma característica a qual não podemos perder de vista, do contrário seria difícil entender um fluxo tão grande de pessoas que se põem a atravessar fronteiras para trabalhar com costura em São Paulo.

Devido a essa razão, o autor sugere que as oficinas de costura não podem ser interpretadas unicamente na perspectiva da exploração da mão de obra. A informalidade e a flexibilidade desses espaços seriam elementos que facilitariam 
a integração dos migrantes ao mercado de trabalho (entre pessoas conhecidas, normalmente parentes ou amigos de amigos), falando a mesma língua e assimilando novos códigos sociais, teriam a oportunidade de aprender o ofício da costura (em geral, não se exige o conhecimento prévio), sem constrangimentos do empregador para a regularização da situação no país (SOUCHAUD, 2012, p. 80).

No entanto, os mesmos aspectos apontados por Souchaud como vantajosos, por permitirem a inserção na cidade, alguns casos de ascensão social e a realização dos projetos migratórios, podem implicar em uma problemática relação ampliada entre a intermediação da migração, a moradia no mesmo local de trabalho e a remuneração por produtividade. As oficinas dos migrantes têm como característica distintiva também serem recorrentemente espaços de moradia, com hospedagem e alimentação. Por vezes, até mesmo o deslocamento para a nova cidade pode ser financiado pelo dono da oficina. Esta relação não tem um significado homogêneo para o conjunto dos migrantes, mas é a partir dela que surgem situações limites como retenção de documentos, endividamentos, coações e restrições de mobilidade. Esses elementos compõem as denúncias de situações extremas de exploração, realizadas por entidades sociais de apoio aos migrantes e pelos próprios migrantes, assim como autuações do Ministério Público do Trabalho (MPT) e do Ministério do Trabalho e Emprego (MTE) de redução do trabalhador à condição análoga à de escravo ${ }^{6}$ (categoria do código penal mobilizada por auditores fiscais e procuradores do trabalho).

O lugar que vem sendo ocupado pelos migrantes na indústria de confecções em São Paulo ganhou corpo no processo de reestruturação produtiva a partir dos anos 1980 e foi intensificado nos anos 1990. De acordo com Branislav Kontic, antes a firma concentrava internamente diversas etapas do processo produtivo e de distribuição, em um modelo de produção em que a economia de escala garantida pela demanda estável ou crescente implicava um padrão de divisão técnica e social do trabalho com uma linha de produção em série, onde se separava o planejamento da execução, com a lógica de um operador por tarefa e máquina (KONTIC, 2001, p. 44-45).

Nos anos 1980, muitas das firmas que se inspiravam nessa estrutura organizacional faliram; outras saíram da região metropolitana de São Paulo, e instalaram suas empresas no nordeste e sul do país; outras tentaram se amoldar ao novo período, mudaram sua estrutura produtiva, diminuíram suas plantas e se especializaram em diferentes segmentos da produção. As empresas buscaram se adaptar às novas exigências do mercado. Neste processo, a subcontratação se generalizou e a etapa da costura, momento da produção caracterizado por ser altamente intensivo em força de trabalho, passou a ser majoritariamente um serviço externo contratado pelas empresas como estratégia de gestão de mão de obra.

Devido às novas condições do mercado, caracterizada pela produção flexível, que combina alta produtividade, pequena escala de produção, diversificação de produtos e exploração de nichos de mercado em função das variações de 
tendências da moda, verificou-se uma profunda mudança nas formas de gestão da mão de obra (KONTIC, 2001, 2007; GARCIA e CRUZ-MOREIRA, 2004). A subcontratação de oficinas de costura não deve ser entendida como simples expediente para a redução de custos trabalhistas, mas sobretudo como um modo de gestão da produção. Com a compressão do intervalo de tempo entre o design da peça, sua confecção e consecutiva venda, as empresas responsáveis pela distribuição demandam produtos exclusivamente quando avaliam momento oportuno para venda no mercado.

O processo de reestruturação acompanhou uma fragmentação na cadeia das confecções entre empresas de acordo com os tipos de serviços prestados. No topo da cadeia estão as empresas ligadas à distribuição, são elas as grandes marcas e lojas de departamento que dominam o comércio varejista e estão presentes nos principais centros de consumo do país. Elas dinamizam toda a cadeia produtiva, pois as suas ordens de serviço ditam o ritmo de trabalho no outro extremo da cadeia - as oficinas de costura, fazendo oscilar períodos de muito volume de trabalho e prazos apertados e outras épocas em que a falta de encomendas é motivo de preocupação, de modo que as oficinas de costura são bastante dependentes do circuito de encomendas ativado pelas empresas do topo da cadeia (FREIRE, 2008). Em seguida, estão situadas as empresas confeccionistas que propriamente fabricam as roupas. Elas se concentram no Brás e no Bom Retiro, mas também se dispersaram pela zona leste e até para outros municípios da região metropolitana de São Paulo, como Guarulhos, e mesmo para fora da RMSP, como no polo têxtil de Americana. Ao longo dos anos 1990, elas diminuíram suas estruturas, concentrando-se nas tarefas de criação, modelagem e corte dos tecidos, além das vendas diretas através das lojas-fábrica.

De acordo com Branislav Kontic (2001), os migrantes coreanos foram importantes na configuração atual do setor. Nos anos 1960 e 1970, chegaram à cidade e abriram pequenas empresas de confecção, onde mobilizavam força de trabalho dos próprios conterrâneos e comercializavam as vestimentas nas regiões em que moravam, especialmente no Bom Retiro. As condições de trabalho se assemelhavam às oficinas de bolivianos e paraguaios atualmente ${ }^{7}$. Conseguiram desenvolver uma estrutura produtiva bastante adaptada ao contexto global, logrando o oferecimento de produtos de qualidade, diferenciados, com valores bastante competitivos. De modo geral, a comunidade coreana apresentava alguns elementos que permitiram a sua atuação destacada no setor - capital inicial para investimento, um modo próprio de financiamento conhecido como sistema Kye, importação e revenda de máquinas industriais de costura, entre outros (KONTIC, 2001; CHOI, 1991). Os coreanos apresentam histórico de migração para as capitais do Paraguai, Bolívia e Argentina, sendo que em alguns casos passaram por estes lugares antes de se estabelecer no Brasil (CHOI, 1991; BUECHLER, 2003). Tanto migrantes paraguaios, como bolivianos que se estabeleceram há mais tempo no setor, relatam que no princípio trabalhavam diretamente como empregados de coreanos. Embora esta relação possa ter sido importante na origem dessas 
dinâmicas migratórias vinculadas à costura, atualmente é impossível caracterizálas como uma relação entre grupos específicos.

No final dos anos 1980 e nos 1990, muitos trabalhadores foram estimulados a abrirem suas próprias oficinas, com doação ou empréstimos de máquinas por seus patrões, a fim de prestarem serviços de costura. Seja no caso das oficinas de brasileiros, muitas delas de ex-operárias das fábricas que perderam seus empregos e passaram a realizar exatamente o mesmo trabalho em seus domicílios, mobilizando parentes e vizinhos para cumprir as encomendas; seja no caso das oficinas de migrantes paraguaios e bolivianos que agenciavam a vinda de parentes e conhecidos diretamente de seus países de origem; ambas se multiplicaram no mesmo período. Na prática, poucas oficinas se constituíram formalmente como empresas e no princípio esse processo foi acompanhado do crescimento da informalidade nas relações de trabalho (embora, como veremos adiante, tenha ocorrido um crescimento da formalização no setor ao longo da última década). O serviço da costura é remunerado por peça confeccionada, recebem-se os tecidos cortados e o demandante estipula o prazo que o prestador terá para realizar a tarefa. Como o segmento é marcado pela sazonalidade e flutuação da demanda, o risco em relação à garantia da reprodução da força de trabalho é exteriorizado para as oficinas de costura. Do mesmo modo que o dono da oficina recebe pagamento pelo volume da encomenda, os operadores das máquinas de costura costumam receber pagamento por peça confeccionada e não por jornada de trabalho.

É certo que a subcontratação não é propriamente uma novidade no setor. Podemos encontrar na pesquisa de Nancy Green (1998), sobre a indústria de vestuário em Nova York e Paris no final do século XIX, situações de sweatshops que podem parecer similares às descrições das condições de trabalho nas oficinas de costura atualmente em São Paulo. Ou mesmo em um contexto mais próximo, a pesquisa de Alice Abreu (1986) sobre trabalho em domicílio na indústria de confecções no Rio de Janeiro, demonstra como nos anos 1970 e 1980 as empresas ligadas à produção de moda com artigos de séries de pequenas escalas, já empregavam este tipo de expediente de trabalho. No entanto, as oficinas de costura subcontratadas se multiplicaram na medida em que o setor se modernizou e se globalizou ${ }^{8}$.

Nessas cadeias produtivas, as chamadas práticas do fast fashion (moda rápida, termo usado pelos grandes varejistas) se espraiaram como uma política de produção em que as marcas, magazines e lojas de departamento passam a ofertar de forma rápida e variante novos modelos, apresentam ao consumidor novas coleções em períodos muito curtos, com as últimas tendências da moda, em um tempo recorde e com preços bastante acessíveis. $O$ fortalecimento dessa política produtiva se deu pela forma como as vendas passaram a indicar o sentido da gestão da própria produção. Diferentemente do pret-à-porter, em que se oferecia uma coleção inteira de uma vez para toda uma temporada, no fast fashion o consumo passa a indicar à empresa em qual sentido e estilo se 
deve produzir. As empresas ficam atentas às suas araras e ativam as encomendas conforme a variação nas vendas; trata-se de outra temporalidade produtiva.

No entanto, nem toda oficina de costura está submetida ao circuito das encomendas de costura. Algumas delas possuem alguma independência através da comercialização direta da produção no mercado popular como, por exemplo, na Feira da Madrugada do Brás, no comércio ambulante e nas galerias que funcionam na região central de São Paulo. Nesses casos, os donos das oficinas apresentam autonomia em relação às encomendas para gerir o tempo e o ritmo da fabricação, ou mesmo uma forma de manter a renda em períodos de baixa das encomendas. A produção varia conforme o ritmo das vendas de suas mercadorias diretamente nas feiras e galerias, que recebem comerciantes de todo o Brasil em busca de mercadorias para a revenda. De modo que estes espaços também apresentam uma grande concentração de paraguaios, bolivianos e de brasileiros que realizam produção própria. São lugares de destaque para a mobilidade migratória na cidade, que estão passando por uma transformação que acompanha o próprio crescimento do consumo popular nos últimos anos (FREIRE, 2014).

\section{Brasileiros, bolivianos e paraguaios na costura}

\section{Perfis}

A comparação entre as oficinas de brasileiros com a de migrantes bolivianos e paraguaios, bem como o perfil de seus trabalhadores, pode fornecer algumas indicações sobre as dinâmicas em curso nesse mercado de trabalho. Em termos da dependência das encomendas de costura, as oficinas dos migrantes não diferem muito das oficinas das ex-operárias das fábricas. Em ambas, recebemse as peças de tecido cortadas, há determinado tempo para confeccioná-las, são remunerados de acordo com a produtividade e o volume das encomendas é flutuante. Não se pode associar o trabalho das oficinas de migrantes ou das brasileiras a determinado tipo de produção de vestimentas, ambas fabricam tanto para os grandes varejistas e grifes famosas, como para o mercado popular, distribuído na Feira da Madrugada, por exemplo.

De acordo com as estimativas sobre jornada de trabalho do Censo de 2010 para operadores de máquina de costura, é plausível que as oficinas de migrantes trabalhem por prazos relativamente menores. Isto é, que executem jornadas mais intensivas e extensivas que as oficinas de brasileiros e talvez até mesmo por preços mais baixos. Na tabela abaixo, verifica-se que $44,9 \%$ dos bolivianos e $38,4 \%$ dos paraguaios ocupados com costura excedem jornada de 44 horas semanais. Ainda que entre os brasileiros o percentual também seja alto $(27,1 \%)$, os migrantes estão mais representados nas jornadas que extrapolam o período regulamentar conforme a CLT. 
O maior número de horas trabalhadas não se traduz necessariamente em um maior rendimento. Entre os três grupos, a grande maioria recebia em 2010 de um a dois salários mínimos, mas destaca-se que para todos era muito elevado o percentual dos que auferiam apenas até um salário mínimo, sendo 31,0\% dos bolivianos, $31,8 \%$ dos brasileiros e $44,5 \%$ dos paraguaios. Dos que ganhavam mais de dois salários mínimos, os brasileiros representavam 18,0\%, enquanto bolivianos e paraguaios representam $12,1 \%$ e $10,6 \%$, respectivamente. Ou seja, relativamente há um percentual maior de brasileiros entre os que ganhavam mais, apesar de exercerem jornadas menores comparativamente com os migrantes (Tabela 1).

Tabela 1 - Distribuição percentual dos ocupados com costura por país de nascimento segundo faixas de jornada de trabalho semanal e rendimentos*. RMSP, Censo 2010.

\begin{tabular}{|c|c|c|c|c|}
\hline & \multirow{2}{*}{ Característica } & \multicolumn{3}{|c|}{ Pais de nascimento } \\
\hline & & Bolívia & Paraguai & Brasil \\
\hline \multirow{8}{*}{ 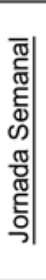 } & Até 20h & 9,8 & 17,3 & 17,9 \\
\hline & De $21 \mathrm{~h}$ a $29 \mathrm{~h}$ & 0,2 & - & 1,8 \\
\hline & De $30 \mathrm{~h}$ a $39 \mathrm{~h}$ & 3,6 & - & 6,9 \\
\hline & De $40 \mathrm{~h}$ a $44 \mathrm{~h}$ & 41,5 & 44,3 & 46,3 \\
\hline & De $45 \mathrm{~h}$ a $50 \mathrm{~h}$ & 28,3 & 16,0 & 17,5 \\
\hline & De $51 \mathrm{~h}$ a $59 \mathrm{~h}$ & 7,1 & 4,0 & 1,9 \\
\hline & $60 \mathrm{~h}$ ou mais & 9,5 & 18,4 & 7,7 \\
\hline & Total & 100,0 & 100,0 & 100,0 \\
\hline \multirow{11}{*}{ 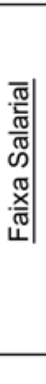 } & Sem rendimentos & 0,7 & - & 1,1 \\
\hline & De $R \$ 0,01$ até $R \$ 127,50$ (até $1 / 4$ SM) & - & - & 1,4 \\
\hline & De $R \$ 127,51$ até $R \$ 255,00$ (de $1 / 4$ até $1 / 2$ SM) & 0,1 & 5,6 & 4,3 \\
\hline & De $R \$ 255,01$ até $R \$ 510,00$ (de $1 / 2$ até $1 S M$ ) & 30,2 & 38,9 & 25,0 \\
\hline & De $R \$ 510,01$ até $R \$ 1.020,00$ (de 1 até 2 SM) & 56,8 & 44,9 & 50,1 \\
\hline & De $R \$ 1.020,01$ até $R \$ 1.530,00$ (de 2 até 3 SM) & 6,5 & 7,8 & 10,0 \\
\hline & De $R \$ 1.530,01$ até $R \$ 2.550,00$ (de 3 até 5 SM) & 4,8 & 2,8 & 5,9 \\
\hline & De $R \$ 2.550,01$ até $R \$ 5.100,00$ (de 5 até $10 \mathrm{SM}$ ) & 0,7 & - & 1,7 \\
\hline & De $R \$ 5.100,01$ até $R \$ 10.200,00$ (de 10 até 20 SM) & 0,2 & - & 0,4 \\
\hline & Total relativo & 100,0 & 100,0 & 100,0 \\
\hline & Total absoluto & 11.807 & 1.242 & 142.739 \\
\hline
\end{tabular}

Fonte: IBGE, Censo Demográfico 2010.

Tabulação Expertise Social Ltda.

Elaboração Própria.

*Salário mínimo de 2010 equivalente a R\$ 510,00

Ao se comparar o perfil de brasileiros ocupados com costura com o de imigrantes, uma diferença marcante se refere à distribuição percentual de gênero dos trabalhadores. No caso dos brasileiros, há predominância de mulheres; no caso dos migrantes a presença de homens é majoritária nos dois casos. Segundo os microdados do Censo de 2010, das pessoas nascidas no Brasil e ocupadas com costura na RMSP, 90,8\% são mulheres. Frequentemente, elas são migrantes internas, majoritariamente do nordeste do país. No caso dos migrantes transnacionais, há mais homens empregados que mulheres: $63,9 \%$ 
dos paraguaios e $55,6 \%$ dos bolivianos empregados com costura são do sexo masculino (Tabela 2).

Em relação às faixas etárias, observa-se que 33,8\% dos brasileiros ocupados com costura têm 50 anos ou mais. Entre os migrantes, apenas 1,2\% dos bolivianos e $2,5 \%$ dos paraguaios estão na mesma faixa etária. Os migrantes ocupados no setor são bem mais jovens do que os brasileiros, especialmente no caso dos paraguaios, entre os quais $69,4 \%$ têm até 29 anos; os bolivianos nessa faixa seriam $63 \%$, já os brasileiros apenas $17,8 \%$. Na média, os brasileiros são mais velhos do que os migrantes transnacionais, que em sua maioria são mais jovens (Tabela 2).

Tabela 2 - Distribuição percentual dos operadores de máquinas de costura por país de nascimento segundo sexo, nível de instrução e faixa etária. RMSP, Censo 2010.

\begin{tabular}{|c|c|c|c|c|}
\hline \multirow{2}{*}{\multicolumn{2}{|c|}{ Característica }} & \multicolumn{3}{|c|}{ País de nascimento } \\
\hline & & Bolívia & Paraguai & Brasil \\
\hline \multirow{3}{*}{$\begin{array}{l}\text { खx } \\
\omega\end{array}$} & Masculino & 55,6 & 63,9 & 9,2 \\
\hline & Feminino & 44,4 & 36,1 & 90,8 \\
\hline & Total relativo & 100,0 & 100,0 & 100,0 \\
\hline \multirow{5}{*}{ 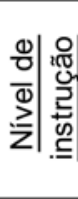 } & Sem instrução e fundamental incompleto & 36,2 & 32,1 & 46,7 \\
\hline & Fundamental completo e médio incompleto & 26,0 & 43,3 & 25,2 \\
\hline & Médio completo e superior incompleto & 36,7 & 24,6 & 26,8 \\
\hline & Superior completo & 1,2 & - & 1,3 \\
\hline & Total relativo & 100,0 & 100,0 & 100,0 \\
\hline \multirow{9}{*}{ 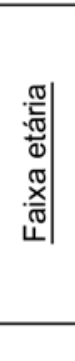 } & Até 12 anos & 0,4 & - & 0,3 \\
\hline & De 13 a 18 anos & 3,6 & 13,6 & 2,7 \\
\hline & De 19 a 29 anos & 58,9 & 55,8 & 14,8 \\
\hline & De 30 a 39 anos & 26,0 & 18,8 & 20,0 \\
\hline & De 40 a 49 anos & 9,9 & 9,3 & 28,4 \\
\hline & De 50 a 59 anos & 0,3 & 2,5 & 22,2 \\
\hline & 60 anos ou mais & 0,9 & - & 11,6 \\
\hline & Total relativo & 100,0 & 100,0 & 100,0 \\
\hline & Total absoluto & 11.807 & 1.242 & 142.739 \\
\hline
\end{tabular}

Fonte: IBGE, Censo Demográfico 2010.

Tabulação Expertise Social Ltda.

Elaboração Própria.

Em termos de escolaridade, as estimativas dos microdados do Censo para nível de instrução apontam que o percentual de pessoas sem instrução ou com fundamental incompleto entre os brasileiros na costura, que corresponde a $46,7 \%$, é maior do que entre os migrantes: $36,2 \%$ para os bolivianos e $32,1 \%$ para os paraguaios. A maior participação dos paraguaios conforme nível de instrução concentra-se no fundamental completo e médio incompleto, com $43,3 \%$. Entre os bolivianos, a maior parcela estaria concentrada entre médio completo e superior incompleto, com 36,7\% (Tabela 2). Destaca-se, de modo geral, que a 
escolaridade dos brasileiros no setor é menor do que a dos migrantes, sendo que os bolivianos apresentam maiores concentrações nos estratos mais escolarizados e os paraguaios estariam em posição intermediária.

De modo sucinto, o perfil médio dos brasileiros ocupados com costura é predominantemente feminino, com idade superior a quarenta anos e nível de instrução relativamente menor. Já o perfil dos migrantes transnacionais é de maioria masculina, majoritariamente com escolaridade de médio completo e com uma concentração muito grande de homens jovens com menos de 29 anos. As características de gênero predominantemente masculino e idade abaixo dos 29 anos são ainda mais destacadas entre os migrantes paraguaios. Isso pode ser atribuído ao fato de que mais da metade dos migrantes paraguaios entraram no país depois de 2005, apresentando um crescimento relativo recente maior que o da migração boliviana. Sylvain Souchaud (2012), ao constatar essa diferença de idade, sugere que possa haver uma tendência de substituição da força de trabalho nacional pela de migrantes, na medida em que há poucos jovens brasileiros ocupando estas posições, o que poderia indicar falta de interesse pelo setor. Segundo o autor, isso indicaria uma tendência comum em outros contextos em que trabalhos menos remunerados e mais precários são ocupados por migrantes.

No entanto, isso ocorre dentro de uma reconfiguração do mercado de trabalho do setor. Talvez mais adequado fosse falar em uma recomposição, pois não é que um grupo esteja sendo preterido em concorrência com o outro. Além disto, existe um espaço neste setor que está sendo criado tanto pelas oficinas de brasileiros como dos migrantes que diz respeito à distribuição direta nos mercados populares, ou seja, não se trata exatamente da substituição de um lugar que já existia, mas também da alocação em novas posições que foram produzidas especialmente na última década.

\section{Oficinas}

As oficinas de costura, tanto de brasileiros como de migrantes, geralmente funcionam em um espaço determinado do ambiente domiciliar, na própria residência dos proprietários das oficinas (os oficineiros, como costumam ser chamados): em um cômodo reservado, na garagem, no terraço, no fundo de quintal, raramente em um espaço desagregado da casa. No entanto, enquanto as brasileiras empregadas em oficinas retornam a seus lares após o expediente, os migrantes moram e trabalham no mesmo espaço. Essa situação pode engendrar os maiores problemas no modo de inserção dos migrantes nas confecções. Os limites do tempo de trabalho ficam menos nítidos na confusão entre trabalho e vida doméstica. Desse modo, quando as encomendas são urgentes ou quando há bastante trabalho, é comum que as jornadas se estendam noite adentro. Por vezes, esta forma de remuneração pode até ser considerada vantajosa pelos 
migrantes, como nos relataram alguns paraguaios em visitas às oficinas. Disseram aproveitar, quando havia muitas encomendas, para trabalhar o máximo possível, com o intuito de aumentar seus rendimentos e conseguir enviar mais dinheiro ao Paraguai, ou então para atender a um pedido em troca de um churrasco no domingo, uma tradição paraguaia que também está presente entre os bolivianos.

Os ganhos de cada um dependem diretamente do desempenho produtivo individual. A falta de encomendas afeta os rendimentos dos trabalhadores, assim como ter uma baixa produtividade por conta da falta de experiência ou por motivos de saúde. Mesmo quando a moradia não é cobrada, espera-se certa produtividade que compense a hospedagem. É uma relação de trabalho individualizada que leva em conta o desempenho produtivo de cada um. Portanto, esta abrangência sobre as condições de vida reflete diretamente nas formas de controle sobre o trabalho. A maior parte dos migrantes transnacionais que trabalham em oficinas mora no mesmo local de trabalho, sobretudo aqueles que chegaram mais recentemente. Esse é um fator muitas vezes visto como proveitoso porque reduz os custos de instalação na cidade, principalmente diante da dificuldade colocada aos migrantes para locar um imóvel, ao mesmo tempo em que dispensa os gastos com transporte. As oficinas também oferecem alimentação, é comum entre elas alguém exercer a função de cozinheiro, geralmente as mulheres, ficando responsáveis por preparar a comida para todos os demais. De certa forma, essa redução dos custos de vida não se separa da renda auferida e distribuída desigualmente entre oficineiros e costureiros, bem como das próprias estratégias de engajamento dos migrantes nessas formas de trabalho.

As oficinas de costura, de um modo geral, empregam um número pequeno de trabalhadores; em relação aos migrantes, com base nas observações de campo, podemos dizer que costumam empregar entre cinco e dez pessoas, raramente excedendo a 15 funcionários. O número de trabalhadores está diretamente relacionado à capacidade da oficina para responder às demandas, assim como à renda do oficineiro. A mobilização de vínculos de proximidade, de parentes, amigos e conhecidos na constituição das oficinas é comum para os três grupos, a diferença no caso dos migrantes é que ela pode envolver a circulação a partir do país de origem (embora também ocorra a mobilidade de trabalhadores migrantes entre oficinas na cidade). Entre os migrantes ocupados na costura, existem grandes desigualdades que refletem o tempo em que estão na cidade, se são oficineiros ou empregados, o tamanho da oficina, se tem um ponto de distribuição própria, se tem clientes com boas encomendas.

Segundo os microdados do Censo 2010, em termos de posição na ocupação para os operadores de máquina de costura, $30,7 \%$ dos brasileiros no setor são empregados com carteira de trabalho assinada, enquanto o percentual de bolivianos na mesma condição seria de $10,4 \%$ e de $8,5 \%$ para os paraguaios. Embora o ramo da indústria seja marcado pela informalidade, ela é ainda maior entre os migrantes. Trabalhadores por conta própria e empregados sem carteira 
brasileiros representariam $67,7 \%$, enquanto para bolivianos seria $88,3 \%$ e $90,1 \%$ no caso dos paraguaios. Destaca-se também que entre os bolivianos o percentual dos que se declaram trabalhadores por conta própria $(60,2 \%)$ é maior do que entre brasileiros e paraguaios. Mas de um modo geral, as informações indicam que é grande o percentual dos ocupados com costura que trabalham autonomamente (Tabela 3).

Tabela 3 - Distribuição percentual dos operadores de máquinas de costura por país de nascimento segundo posição na ocupação. RMSP, Censo 2010.

\begin{tabular}{|c|c|c|c|}
\hline \multirow{2}{*}{$\begin{array}{c}\text { Posição na ocupação e } \\
\text { categoria no emprego principal }\end{array}$} & \multicolumn{3}{|c|}{ País de nascimento } \\
\hline & Bolívia & Paraguai & Brasil \\
\hline $\begin{array}{l}\text { Empregada(o) com carteira de } \\
\text { trabalho assinada }\end{array}$ & 10,4 & 8,5 & 30,7 \\
\hline $\begin{array}{l}\text { Empregada(o) sem carteira de } \\
\text { trabalho assinada }\end{array}$ & 28,1 & 45,0 & 23,4 \\
\hline Conta própria & 60,2 & 45,1 & 44,3 \\
\hline Empregadora(or) & 0,8 & 1,4 & 0,6 \\
\hline Não remunerada(o) & 0,5 & - & 1,0 \\
\hline Total relativo & 100 & 100 & 100 \\
\hline Total absoluto & 11.807 & 1.242 & 142.739 \\
\hline
\end{tabular}

A visibilidade das oficinas de migrantes devido a casos extremos de exploração e condições precárias de trabalho, bem como a repercussão midiática da vinculação a grandes marcas e lojas de departamento, parece ter criado uma pressão para a formalização das oficinas. A atuação de entidades de apoio aos migrantes como o Centro de Apoio ao Migrante (CAMI), Centro de Direitos Humanos e Cidadania do Imigrante (CDHIC), Centro Pastoral do Migrante, entre outras, também ocorre nesse sentido, com campanhas de orientação para os oficineiros. No princípio, nas empresas confeccionistas do Brás e do Bom Retiro, encontrava-se com frequência anúncios de "precisase de oficinas de costura", atualmente os mesmos anúncios costumam ser acompanhados da sentença "com CNPJ". Trata-se de uma medida de precaução das empresas para que sua relação com as fornecedoras seja caracterizada formalmente como de prestação de serviços, e não se confunda com uma relação de trabalho ou mesmo um vínculo de emprego. A crescente exigência de formalização das oficinas para contratação como prestadora de serviços ocorre no marco da gestão dos riscos das empresas, para não serem responsabilizadas pelas condições de trabalho. Trata-se de diminuir a possibilidade de receber multas, penalizações ou de terem as marcas vinculadas às ações de auditores fiscais (MTE) e procuradores do trabalho (MPT). 
A evolução no registro de trabalhadores formais da Rais para operadores de máquinas de costura na RMSP demonstra o crescimento acentuado entre os migrantes, sobretudo depois de 2010. No gráfico abaixo, vemos que desde 2003 até 2012 houve um crescimento no registro de trabalhadores formais operadores de máquina de costura para os três grupos, de um quarto para brasileiros, mas em uma variação relativa bem mais elevada entre bolivianos (10 vezes mais) e, principalmente, paraguaios (21 vezes), no entanto o número de início era muito baixo (13 vínculos). 0 crescimento mais substantivo em termos absolutos entre os migrantes transnacionais, deu-se a partir de 2010, quando mais do que dobrou o registro formal para bolivianos e paraguaios na costura, enquanto apresentou uma leve queda de $7,7 \%$ para os brasileiros no mesmo período.

\section{Gráfico 1 - Evolução do registro formal de operadores de máquinas de costura* para brasileiros (eixo à direita), paraguaios e bolivianos (eixo à esquerda).}

RMSP, 2003 a 2012.

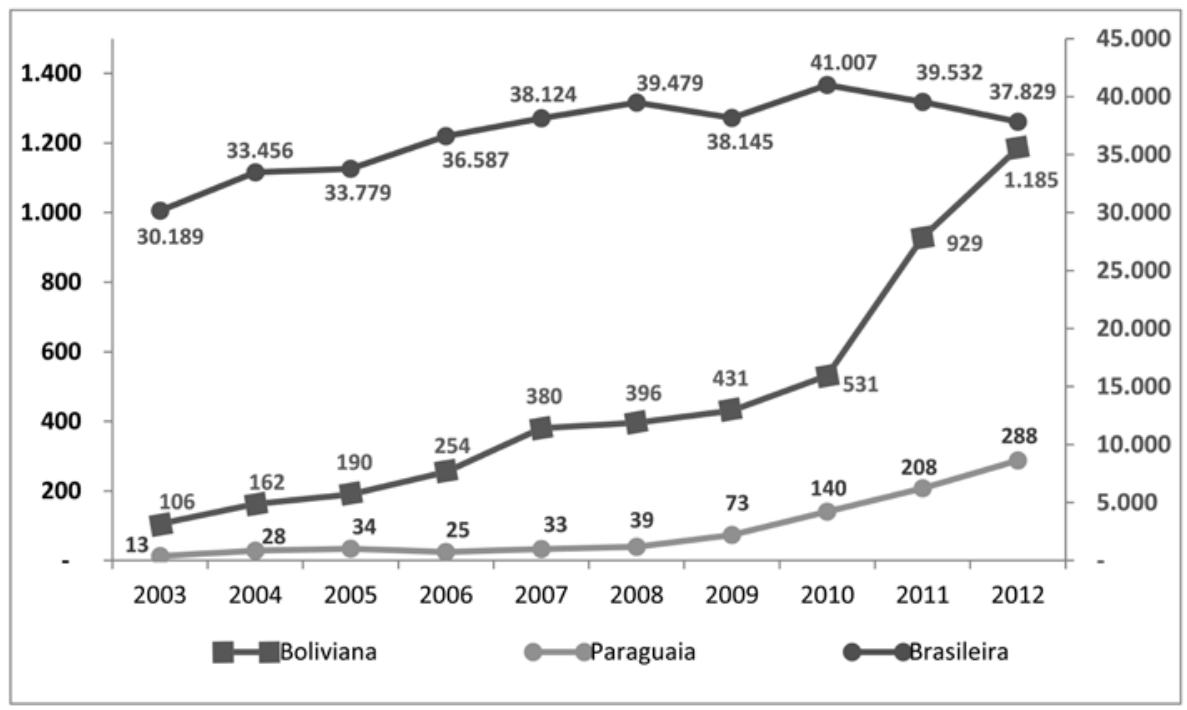

Fonte: Rais

Elaboração própria.

*Foram consideradas duas famílias ocupacionais para selecionar os operadores de máquinas de costura (CBO 2002), são elas: (código 7632) operadores de máquinas para costura de peças do vestuário; (código 7633) operadores de máquinas para bordado e acabamento de roupas.

O Microempreendedor Individual (MEI), figura jurídica criada em 2009, é um mecanismo de registro das oficinas enquanto empresas autônomas, as quais podem obter um CNPJ e estabelecer vínculos formais com os demandantes. 0 MEI permite a abertura de uma empresa que não exceda faturamento de 60 
mil reais anuais, com burocracia simplificada, podendo ser realizada através da internet, e com contratação de no máximo um empregado. A Confecção de peças de vestuário, exceto roupas sob medida foi a quinta maior categoria do MEI para o município de São Paulo, no resultado acumulado até 2014. Quando verificamos o total dos MEls em atividade, segundo a nacionalidade, no município de São Paulo, vemos que os bolivianos constituem a maioria absoluta dos imigrantes que abriram este tipo de empresa, com 5.155 empresas ativas; os paraguaios se situam em quarto lugar, com 395 empresas ativas, o equivalente a $4,1 \%$ dos imigrantes inscritos no MEl até março de 2014 (tabela 4).

Tabela 4. Distribuição e frequência dos estrangeiros inscritos no MEl, segundo nacionalidade. Município de São Paulo, acumulado até maio de 2014.

\begin{tabular}{lrr}
\hline Nacionalidade & Frequência & Distribuição (\%) \\
\hline Boliviana & 5.155 & 54,1 \\
Chinesa & 811 & 8,5 \\
Peruana & 605 & 6,3 \\
Paraguaia & 395 & 4,1 \\
Demais & 2.564 & 26,9 \\
\hline Total & $\mathbf{9 . 5 3 0}$ & $\mathbf{1 0 0 , 0}$ \\
\hline
\end{tabular}

Fonte: Portal do Empreendedor, MDIC (extraído em 10/05/2014). Elaboração própria.

Em que medida a maior formalidade altera os problemas relativos às condições de trabalho no interior das oficinas e qual o seu alcance, ainda não é possível avaliar. $O$ incremento da formalidade aumenta a segurança jurídica para as empresas tomadoras de serviço, mas pouco afeta a lógica das encomendas de prazos curtos e preços baixos pagos por lote. Em todo caso, não se pode dizer que não tenha nenhum impacto sob suas dinâmicas. A situação do conjunto das oficinas não é homogênea. Em dois casos de oficinas paraguaias visitadas em 2013, com 8 e 11 funcionários, sendo uma no bairro da Luz e a outra no bairro do Bom Retiro, os trabalhadores recebiam por jornada (sendo que em uma marcavam ponto), havia refeitórios, extintores e os alojamentos ficavam em imóveis diferentes dos espaços de trabalho, ainda que muito próximos, um do outro lado da rua e o outro em andares diferentes do mesmo prédio. As duas oficinas eram empresas formalmente constituídas. Outro caso de oficina de paraguaios, também no Bom Retiro, onde trabalhavam 12 costureiros, apresentava um cenário bem distinto: instalações elétricas precárias; pouca ventilação; cadeiras sem encosto; fogão e pia no mesmo espaço das máquinas de costura; paredes com infiltrações e mofo. A despeito das condições de trabalho, não seria um grande impedimento essa oficina mobilizar um CNPJ para desenvolver suas atividades como prestadora de serviços. 


\section{Conclusão}

Neste artigo, buscamos discutir a inserção de migrantes que trabalham em oficinas de costura na RMSP. Abordamos como o desenvolvimento recente do segmento se associou com a migração transnacional e a maneira que se situam nesta cadeia produtiva. Em seguida, tratamos de tecer algumas comparações entre os perfis de trabalhadores brasileiros, paraguaios e bolivianos e suas oficinas de costura. De um modo geral, procuramos deslocar a ênfase exclusiva na dimensão étnica ou de origem nacional dos trabalhadores, com o objetivo de compreender semelhanças e diferenças entre as dinâmicas em curso neste mercado de trabalho.

Com isso, não pretendemos reduzir as peculiaridades da migração boliviana ou paraguaia à forma de organização da produção na indústria de confecções em São Paulo. Não foi o objetivo discutir os sentidos da experiência migratória que sempre envolve uma dimensão mais ampla acerca das relações entre origem e destino, assumindo significados específicos para cada grupo em questão. Aqui nos limitamos a refletir sobre o espaço de atividades em torno dos quais diferentes fluxos migratórios se apoiam, seja como uma primeira forma de inserção, como uma passagem temporária ou ainda como uma estratégia de engajamento a longo prazo, sem nunca confundir a migração com a atividade que os migrantes desenvolvem.

Do mesmo modo, o desenvolvimento recente da indústria de confecções não se restringe à atuação de um grupo de migrantes especificamente, sendo antes a confluência e composição entre pessoas de diferentes origens que encontram na costura um lugar de trabalho. Neste sentido, não se trata de uma sucessão consecutiva em que um grupo substitui o outro. A participação dos paraguaios é tão antiga quanto à boliviana, embora em uma escala menor. A ênfase exclusiva em relação aos bolivianos acaba por obscurecer questões que são relativas ao setor de atividade e não à origem de seus trabalhadores, como as precárias condições de trabalho também recorrentes entre os paraguaios e a própria participação de mulheres brasileiras que são a maioria no segmento.

A crítica às condições de trabalho não pode recair unicamente como uma questão dos migrantes que estão engajados na atividade de costura, pois não são determinadas apenas no interior das oficinas. O ritmo de trabalho é dado antes pelas temporalidades que caracterizam a competição no setor. Ao discutir a exploração do trabalho, não estamos colocando isto em uma acepção moral, haja vista que ela é inerente aos processos produtivos na sociedade capitalista. Neste sentido, a perspectiva da ascensão social que ocorre entre algumas pessoas neste circuito e o migrante como sujeito nessa dinâmica, conforme expressa a ideia de projetos migratórios, não são contrapontos à exploração do trabalho. A perspectiva de ascensão social, seja ao tornar-se dono de oficina, seja ao acumular recursos para investir em outras atividades na própria cidade ou no país de origem, é um aspecto que compõe um conjunto de possibilidades, também relevante em termos da subjetivação em torno dessas formas de trabalho entre os migrantes. 
As condições dos migrantes neste setor de atividade não são homogêneas, para se pensar as estratégias de engajamento dos migrantes deve-se levar em conta os múltiplos aspectos que compõem a dinâmica das oficinas de costura. As possibilidades para um migrante recém-chegado que trabalha como costureiro não são as mesmas daqueles que chegaram no decorrer dos anos 1980 e 1990, e que hoje se encontram como donos de oficinas. Como também não são iguais entre oficineiros que apenas trabalham com encomendas reféns da sazonalidade das demandas e aqueles que possuem um ponto nos mercados populares do centro e linhas de comercialização próprias.

\section{Notas}

1 - Para mais informações, ver a pesquisa de Branislav Kontic (2001) e Garcia e Cruz-Moreira (2004) que tratam, dentre outros temas, da relação histórica de migrantes transnacionais com a indústria têxtil e de confeç̧ões.

2 - Esse percentual considera toda a população nascida nesses países e residentes na RMSP, não se trata apenas da População Economicamente Ativa. Considerando-se apenas as pessoas ocupadas, tem-se $64,3 \%$ dos bolivianos e $41,7 \%$ dos paraguaios residentes na RMSP como Operadores de máquinas de costura. Esses percentuais não englobam Trabalhadores qualificados da preparação de confecções, Costureiros, bordadeiros e afins, dentre outras ocupações.

3 - Informações do Registro Anual de Informações Sociais (Rais) geradas no sistema online Dardo do Ministério do Trabalho e Emprego. A Rais é um registro administrativo obrigatório que todas as empresas devem realizar para o MTE. Esse dado se refere ao número de vínculos ativos em 31/12/2012 dos trabalhadores da indústria de transformação por grupo CNAE (Classificação Nacional de Atividade Econômica, versão 2.0), sendo que a Confecção de artigos do vestuário e acessórios ocupava posição de destaque. Entre 2006 e 2012, este é o grupo com a maior participação de vínculos ativos na indústria de transformação da RMSP.

4 - Analisou-se apenas as duas principais famílias da CBO (Classificação Brasileira de Ocupações) em que atuam os operadores de máquinas de costura na RMSP em 2012, a de Operadores de máquinas para costura de peças do vestuário e Operadores de máquinas para bordado e acabamento de roupas.

5 - Para uma discussão detalhada sobre "projeto migratório", lara Rolnik Xavier (2010) trabalhou o conceito em sua pesquisa sobre a migração boliviana em São Paulo.

6 - Isso não deve ser tomado como uma característica das oficinas de costura em geral ou como uma categoria analítica das migrações em torno do setor. Trata-se do artigo 149 do código penal brasileiro que por vezes é mobilizada para as autuações em oficinas de costura. Neste sentido, são situações limites que assim foram encaminhadas por procuradores e auditores fiscais no campo jurídico. Para maiores informações, ver dossiê de matérias publicadas pela ONG Repórter Brasil sobre casos de exploração de força de trabalho migrante em oficinas de costura da RMSP, disponível em:< http://reporterbrasil.org.br/2012/07/especial-flagrantesde-trabalho-escravo-na-industria-textil-no-brasil/>. Acesso em: 30 jun. 2014.

7 - As primeiras notícias sobre trabalhadores migrantes em situação precária nas confecções de São Paulo falam justamente dos coreanos, que durante um período de restrição à migração, entravam irregularmente no país através do Paraguai a fim de trabalhar para seus compatriotas na costura (ver: O Estado de São Paulo. Costurar escondido o meio de sobrevivência - 
02/02/1982). Para mais informações sobre a migração coreana e as confecções, ver: Choi (1991); Kontic (2001); Buechler (2003); Freitas (2009) e Souchaud (2012).

8 - Segundo publicação da CNI/ABIT (2012), em 2009, o Brasil apareceu em quarto lugar, com $2,9 \%$ da produção mundial de vestuário. A maior parte da produção global estaria concentrada em países asiáticos: a China com 48,96\%, a Índia com 7,00\%, e o Paquistão com 3,81\%. Com exceção da Itália, que aparece em sétimo (com 2,4\%), nota-se que os países do capitalismo avançado não figuram entre os quinze maiores produtores de vestuário do globo. De todo modo, ainda que o Brasil esteja na quarta posição em termos de produção, isso não quer dizer que o país seja um grande exportador, na realidade o país importa mais do que exporta e a sua produção é destinada majoritariamente para o mercado nacional. Desde os anos 1970, inúmeras pesquisas em diferentes contextos vêm identificando a utilização de oficinas de costura, que recorrentemente empregam migrantes, muitas vezes em situação irregular no país. Para citar apenas alguns exemplos, podemos elencar os respectivos autores e seus estudos: Green (1998) - estudo comparativo da indústria de vestuário na França (Paris e interior) e nos EUA (Nova lorque e Califórnia), dos anos 1880 aos 1980; Sassen (In: Portes, et. al., 1989) - análise do setor em Nova lorque, dos anos 1970 aos 1980; Morokawasic-Muller (1990) trata de migrantes na indústria de confecções em Paris; Bonacich tem uma longa trajetória com estudos sobre a indústria de confecções e a migração, sendo Los Angeles a sua maior referência, seus estudos apontam o emprego de migrantes de diversos países diferentes (2000, 2002); Ruggiero (2000) aborda os migrantes chineses que trabalham em oficinas em Milão, dentre outros estudos.

9 - O mesmo quadro de análise do perfil realizado para o Censo foi feito para a Rais, que trata exclusivamente dos trabalhadores formais. De modo geral, as mesmas características encontradas na totalidade dos operadores de máquinas de costura podem ser observadas no recorte exclusivo dos trabalhadores formalizados.

\section{Distribuição percentual dos operadores formalizados de máquinas de costura por nacionalidade segundo sexo, escolaridade e faixa etária*. RMSP, Rais 2012.}

\begin{tabular}{|c|c|c|c|c|}
\hline & \multirow{2}{*}{ Característica } & \multicolumn{3}{|c|}{ Nacionalidade } \\
\hline & & Boliviana & Paraguaia & Brasileira \\
\hline \multirow{11}{*}{$\begin{array}{l}\vec{x} \\
\text { ஸे }\end{array}$} & Masculino & 66,9 & 68,8 & 13,1 \\
\hline & Feminino & 33,1 & 31,3 & 86,9 \\
\hline & Total & 100,0 & 100,0 & 100,0 \\
\hline & Analfabetos e até $5^{a}$ Incompleto & 0,9 & 0,3 & 2,1 \\
\hline & $5^{\mathrm{a}}$ Completo Fundamental & 2,2 & 3,1 & 5,1 \\
\hline & $6^{\mathrm{a}}$ a $9^{\mathrm{a}}$ Fundamental & 4,3 & 8,0 & 10,7 \\
\hline & Fundamental Completo & 29,3 & 33,3 & 22,5 \\
\hline & Médio Incompleto & 12,7 & 13,5 & 12,1 \\
\hline & Médio Completo & 48,7 & 40,6 & 46,6 \\
\hline & Superior Completo e Incompleto & 1,9 & 1,0 & 0,9 \\
\hline & Total & 100,0 & 100,0 & 100,0 \\
\hline \multirow{9}{*}{ 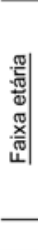 } & 15 a 17 & 0,1 & 0,3 & 0,7 \\
\hline & 18 a 24 & 25,8 & 25,3 & 9,7 \\
\hline & 25 a 29 & 24,7 & 29,9 & 10,2 \\
\hline & 30 a 39 & 36,2 & 28,8 & 25,4 \\
\hline & 40 a 49 & 10,5 & 12,2 & 30,4 \\
\hline & 50 a 64 & 2,6 & 3,5 & 22,8 \\
\hline & 65 ou mais & - & - & 0,9 \\
\hline & Total & 100,0 & 100,0 & 100,0 \\
\hline & Total absoluto & 1.185 & 288 & 37.829 \\
\hline
\end{tabular}

Fonte: Rais. Elaboração própria.

*Foram consideradas duas famílias ocupacionais para selecionar os operadores de máquinas de costura (CBO 2002), são elas: (código 7632) operadores de máquinas para costura de peças do vestuário; (código 7633) operadores de máquinas para bordado e acabamento de roupas. 


\section{Referências}

ABREU, Alice Rangel de Paiva. O avesso da moda: trabalho a domicílio na indústria da confecção. São Paulo: Ed. Hucitec, 1986.

BONACICH, Edna; APPELBAUM, Richard. Behind the label: inequality in the Los Angeles apparel industry. Berkeley e Los Angeles: University of California Press, 2000.

BONACICH, Edna. Labor's responde to global production. In: GEREFFI, G.; SPENER, D. e BAIR, J. Free trade and uneven development. Philadelfia: Temple University Press, 2002, p. 123-138.

BUECHLER, Simone. Sweating it in the Brazilian Garment Industry: Bolivian workers and global economic forces in São Paulo. Nova lorque: Metropolitan Studies, New York University, 2003.

CHOI, Keum Joa. Além do arco-íris: a imigração coreana no Brasil. São Paulo: dissertação de mestrado, FFFLCH-USP, 1991.

CÔRTES, Tiago Rangel. Os migrantes da costura em São Paulo: retalhos de trabalho, cidade e Estado. São Paulo: dissertação de mestrado, FFLCH-USP, 2013.

FREIRE DA SILVA, Carlos. Trabalho informal e redes de subcontratação: dinâmicas urbanas da indústria de confecções em São Paulo. São Paulo: dissertação de mestrado, FFLCH-USP, 2008.

FREIRE DA SILVA, Carlos. Das calçadas às galerias: mercados populares do centro de São Paulo. São Paulo: tese de doutorado, FFLCH-USP, 2014.

FREITAS, Patrícia Tavares de. Imigração e Experiência Social: o circuito de subcontratação transnacional de força de trabalho boliviana para o abastecimento de oficinas de costura na cidade de São Paulo. Campinas: Dissertação de mestrado, UNICAMP, 2009.

GARCIA, Renato; CRUZ-MOREIRA, Juan. O Complexo têxtil-vestuário: um clusterresistente. In: COMIN, Álvaro (org.). Caminhos para o Centro: estratégias de desenvolvimento para a região central. São Paulo: CEBRAP/EMURB/CEM, 2004.

GREEN, Nancy L. Du sentier à la 7e avenue. Paris: Seuil, 1998.

KONTIC, Branislav. Aprendizado e metrópole: a reestruturação produtiva da indústria de vestuário em São Paulo. São Paulo: dissertação de mestrado, sociologia - USP, 2001.

KONTIC, Branislav. Inovação e redes sociais: a indústria da moda em São Paulo. São Paulo: tese de doutorado, sociologia, USP, 2007.

MOROKAVASIC - MULLER, Mirjana. The underside of fashion: immigrants in the parisian garment industry". Universidade da Califórnia: Los Angeles, 1990. (paper apresentado no Institute for Social Science Ressearch). Disponível em: <http://www.escholarship.org/ uc/item/4217p95h\#page-2>. Acesso em: 11 jun. 2013.

RUGGIERO, Vincenzo. Crime and Markets: Essays in Anti-Criminology. Oxford: Oxford University Press, 2000.

SASSEN, Saskia. New York city's informal economy. In: PORTES, Alejandro; CASTELLS, Manuel ; BENTON, Lauren. The Informal Economy. Studies in Advanced and Less Developped Countries. Baltimore and London. The John Hopkins Press Ltd, 1989.

SOUCHAUD, Sylvain. A confecção: nicho étnico ou nicho econômico para a imigração latinoamericana em São Paulo? In: BAENINGER, Rosana (Org.). Imigração boliviana no Brasil. Campinas: NEPO/Unicamp, 2012.

XAVIER, lara Rolnik. Projeto migratório e espaço: os migrantes bolivianos na RMSP. Campinas: Dissertação de Mestrado, UNICAMP, 2010. 


\title{
RESUMO
}

O objetivo deste texto é discutir a inserção de migrantes transnacionais na costura. Defendese que os problemas relacionados às condições de trabalho, às violações e situações a que são submetidos os trabalhadores não decorrem da origem nacional dos migrantes, mas sim do modo como se associa a migração à organização do trabalho nessa indústria reestruturada. A primeira parte do texto aborda a afinidade existente entre os modos como se estruturam a produção pulverizada de vestimentas em oficinas de costura e os atuais fluxos migratórios transnacionais. Num segundo momento são traçadas algumas comparações entre a organização de oficinas de costura de bolivianos, paraguaios e brasileiros e o perfil de seus trabalhadores, sendo que o grande diferencial das oficinas de migrantes se deve ao modo pelo qual se articulam as condições de trabalho, a moradia e a intermediação migratória. Ao considerar a presença de paraguaios no setor, busca-se deslocar a problematização étnica ou da origem nacional desses trabalhadores e evidenciar o funcionamento desse mecanismo de exploração de trabalho que, ao mesmo tempo, permite a inserção de migrantes transnacionais na vida urbana de São Paulo.

Palavras-chave: indústria de confecções; migração transnacional; subcontratação.

\begin{abstract}
The objective of this paper is to discuss the insertion of transnational migrants in the sewing industry. It is argued that the problems related to working conditions, violations and the situations that workers are subjected to do not derive from their national origin, but from the way migration is associated with the productive processes of this restructured industry. The first part of the text deals the structure of the sprayed production of garments in sewing workshops and its relation to the current transnational migration. Secondly, some comparisons are drawn between how workshops of Bolivians, Paraguayans and Brazilians are organized and the profile of their workers. It is argued that the major difference of migrant workshops is due to the way in which they articulate the conditions of work, housing and immigration intermediation. When considering the presence of Paraguayans in this industry, the paper seeks to shift from the ethnic or national problematic and highlight the functioning of this labor exploitation mechanism which, at the same time, allows for the inclusion of transnational migrants in the urban life of São Paulo.
\end{abstract}

Keywords: garment industry; transnational migration; subcontracting. 


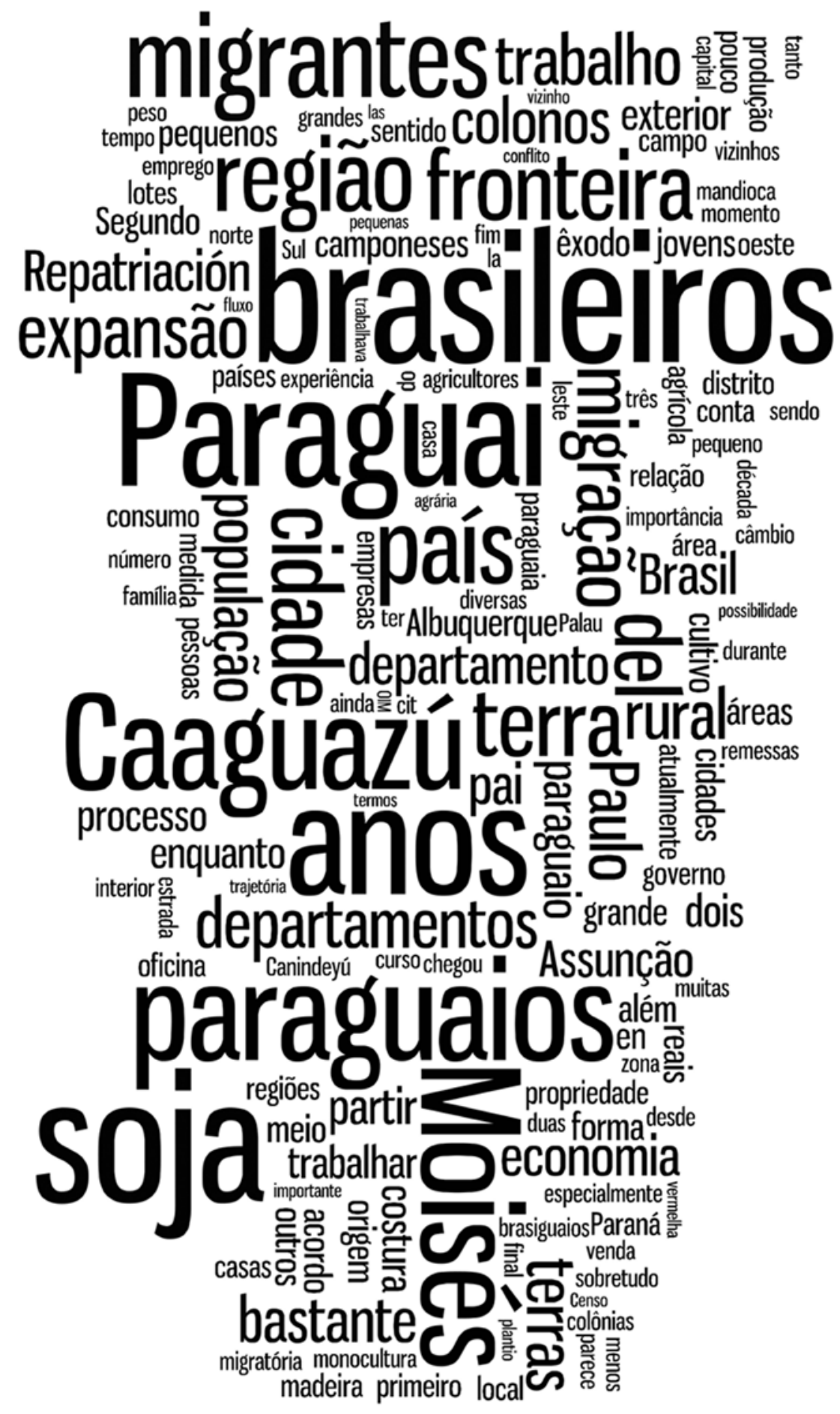


